\title{
Splinting of Implants and Adjacent Natural Teeth for Esthetic Correction in Anterior Maxilla: A Case Report
}

\author{
Ananya S Venkatesan ${ }^{1}$, Vinoth Kumar ${ }^{2}$, Pratebha Balu ${ }^{3}$, Karthikeyan Ilangovan ${ }^{4}$, Vineela K Reddy ${ }^{5}$, Saravana K Ravindran ${ }^{6}$
}

\begin{abstract}
The therapeutic goal of implant dentistry is not merely tooth placement but total oral rehabilitation. Implants provide excellent support for fixed appliances, increasing function as compared to conventional dental therapies. For long-term success of the procedure, the biomaterials, the mechanics used, and also the patient's cooperation for maintenance play a key role. The placement of dental implants in the anterior maxilla is a challenge for clinicians because of patients exacting demands and difficult preexisting anatomy. The esthetic restoration of anterior maxillary incisor area is critical to a successful outcome. This case report describes the placement of implant in the anterior maxillary region splinted with endodontically treated adjacent natural teeth and restoration of adjacent teeth to obtain an esthetic smile.
\end{abstract}

Keywords: Implant and natural teeth connection, Maxillary anterior esthetics, Tooth and implant supported prosthesis.

Journal of Scientific Dentistry (2019): 10.5005/jp-journals-10083-0914

\section{INTRODUCTION}

A pleasant smile is an essential factor in modern society. Smile is a person's ability to express a range of emotions and is connected to his/her, self-esteem and confidence in the society. A confident smile cannot be obtained without esthetic teeth. The presence of unesthetic teeth makes a person too embarrassed which becomes the sources for lack of self-esteem and self-confidence. Esthetic dentistry enhances a person's smile by improving the appearance of teeth based on several aspects such as shape, hue, size, position, and its relationship to adjacent teeth. A multidisciplinary approach by the involvement of various specialties helps in providing the patient with a more esthetic smile. This includes esthetic dentistry, placement of implants, orthodontics correction, operative, and periodontal therapy. ${ }^{1}$

An esthetic restoration in an anterior maxillary region following placement of implants poses a challenge for the success of treatment. It requires exact implant positioning, soft and hard tissue management, presurgical, and prosthetic planning. Hence, it should be approached with caution to minimize esthetic complications postoperatively. ${ }^{2}$

Splinting of teeth with implants, i.e., tooth implant supported prosthesis can be considered for prosthetic support. ${ }^{3}$ Although a controversy exists in literature on recommendation of splinting implants to natural teeth, various long-term studies have not demonstrated any adverse effects on the same. ${ }^{4-6}$ Belser et al. ${ }^{7}$ suggested that "a combination of implant and tooth support for fixed partial dentures is acceptable."

An implant can be splinted to natural teeth by following certain guidelines: 8

- Implants can be splinted to natural teeth only when teeth needs support

- The fixed prosthesis should not end on the weakest splinted abutment

- Regardless of the connection, teeth must be cemented using definitive cement

- A rigid connector can be used to connect both and avoid occlusal forces in centric and eccentric relations for the implant prosthesis.
1Department of Periodontology and Implantology, Indira Gandhi Institute of Dental Sciences, Puducherry, India

${ }^{2-6}$ Department of Periodontology, Indira Gandhi Institute of Dental Sciences, Sri Balaji Vidyapeeth (a Deemed University), Puducherry, India Corresponding Author: Vinoth Kumar, Department of Periodontology, Indira Gandhi Institute of Dental Sciences, Sri Balaji Vidyapeeth (a Deemed University), Puducherry, India, Phone: +91 9843353089, e-mail: vinothmessi@gmail.com

How to cite this article: Venkatesan AS, Kumar V, Balu P, Ilangovan K, Reddy VK, Ravindran SK. Splinting of Implants and Adjacent Natural Teeth for Esthetic Correction in Anterior Maxilla: A Case Report. J Sci Den 2019;9(2):53-56.

Source of support: Nil

Conflict of interest: None

The present case explains the correction of esthetics in the anterior maxillary region by splinting the implants with endodontically treated natural teeth and the correction of anatomically varied adjacent teeth in a five-unit bridge.

\section{Case Description}

A 42-year-old female patient reported to the Department of Periodontology, Indira Gandhi Institute of Dental Sciences, with a chief complaint of deposits in her teeth and also to replace her missing upper front teeth. Past medical history revealed that the patient was a systemically healthy patient with no allergy to medications. Past dental history revealed that the patient underwent extraction of 21 due to trauma before 1 year. On intraoral examination, 21 and 22 were missing with peg laterals in relation to 12 , buccally flared 11 and mesially tilted 23 and 24 . Since 23 and 24 were mesially tilted, $3 \mathrm{~mm}$ of space was evident between the two teeth (Fig. 1). On radiographic investigation with orthopantomogram (OPG), congenitally missing 22 , periodontally sound adjacent teeth with adequate bone in relation to edentulous area in 21 was evident (Fig. 2). Based on the clinical findings treatment options such as (1) extraction of flared 11 and placement of immediate implants followed by a 5 -unit bridge and (2) orthodontic treatment along

(c) The Author(s). 2019 Open Access This article is distributed under the terms of the Creative Commons Attribution 4.0 International License (https://creativecommons. org/licenses/by-nc/4.0/), which permits unrestricted use, distribution, and non-commercial reproduction in any medium, provided you give appropriate credit to the original author(s) and the source, provide a link to the Creative Commons license, and indicate if changes were made. The Creative Commons Public Domain Dedication waiver (http://creativecommons.org/publicdomain/zero/1.0/) applies to the data made available in this article, unless otherwise stated. 
with implant placement in relation to 21 followed by prosthesis were explained to the patient. Since the patient was not willing for extraction and orthodontic treatment, a comprehensive treatment plan was put forward, which included root canal treatment (RCT) in relation to 11,12 , and 23 ; implant placement in relation to 21 ; and a 5-unit bridge from 12 to 23 [12 (peg laterals), 11 (flared), 21 (implants), 22 (pontic), and 23 (mesially tilted)]. Also the mesiodistal space between 11 and 23 was inadequate for two crowns and excess for single crown, so mock wax up showed un-esthetic crown even though the crown-root ratio was favorable. A 3.75-mm diameter implant with minimal diameter crown on 21 , along with 22 gave pleasing appearance and patient satisfaction. The patient consented for the same.

\section{Implant Placement}

Placement of the implant was done according to the classic Branemark procedure. Surgical crestal incision was given in 21 region with a no. 15 Bard Parker (BP) blade under local anesthesia, followed by elevation of the full thickness mucoperiosteal flap. Sequential drills starting with $2 \mathrm{~mm}$ pilot drill upto $3.2 \mathrm{~mm}$ drills were used and the osteotomy site was prepared. Implant of dimension $3.75 \times 11.5 \mathrm{~mm}$ was placed, and primary stability was achieved (Fig. 3). Cover screw was placed and the surgical site was covered using simple interrupted sutures (Fig. 4). Periodontal dressing was given following suturing.

Patient was advised to take analgesics [Hifenac-P Bi Daily (BD) (twice a day) for 3 days] and amoxycillin 500 mg three times a day for 3 days along with chlorhexidine digluconate $(0.12 \%)$ rinse twice daily for 10 days and not to brush aggressively in the operated area.

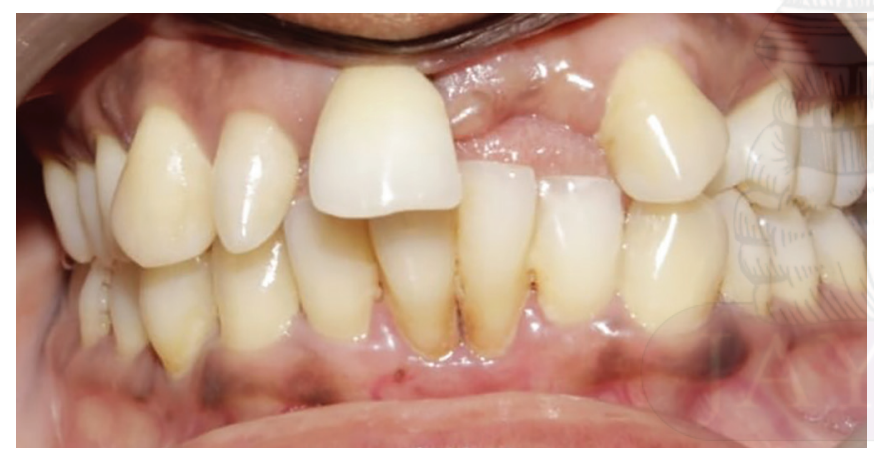

Fig. 1: Preoperative clinical photograph showing missing 21 and 22. Flared 11, mesially tilted 23, peg laterals in 12

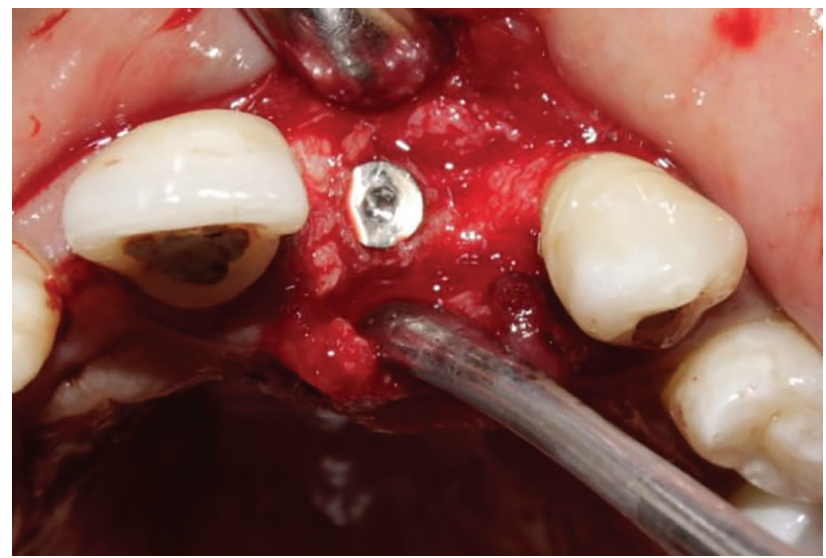

Fig. 3: Flaps raised under LA and implant of size $3.75 \times 11.5 \mathrm{~mm}$ implant placed
Patient was recalled after 10 days and the suture removal was done.

Four months postplacement of implants, patient was recalled and intraoral radiograph was taken for assessing osseointegration of implant, which was observed to be good without any radiolucency. This was followed by second-stage implant surgery, where a healing abutment was placed to create gingival collar (Fig. 5).

After 2 weeks, patient was recalled and healing cap was removed.

Patient was then referred to department of endodontics for intentional RCT of 12, 11, and 23 followed by crown preparation. An open-tray implant-level impression was taken using a transfer coping and implant analog.

A mock-up trial with $15^{\circ}$ angled customized abutment was done. Radiograph was taken to confirm the seating of the abutment (Fig. 6).

The final all-ceramic prosthesis was cemented to the teeth. The patient was satisfied with the final prosthesis and esthetics (Fig. 7).

The patient was followed up for a period of 6 months. No biological or technical complications were observed. The prosthesis was esthetically pleasing and functionally good.

\section{Discussion}

The rehabilitation of an unesthetic smile in maxillary anterior region in this case was a clinical challenge, when it involves missing teeth, and various anatomical and developmental abnormalities such as peg laterals, abnormal spacing between teeth, variation in the position of the teeth such as proclination and rotation. Hence,

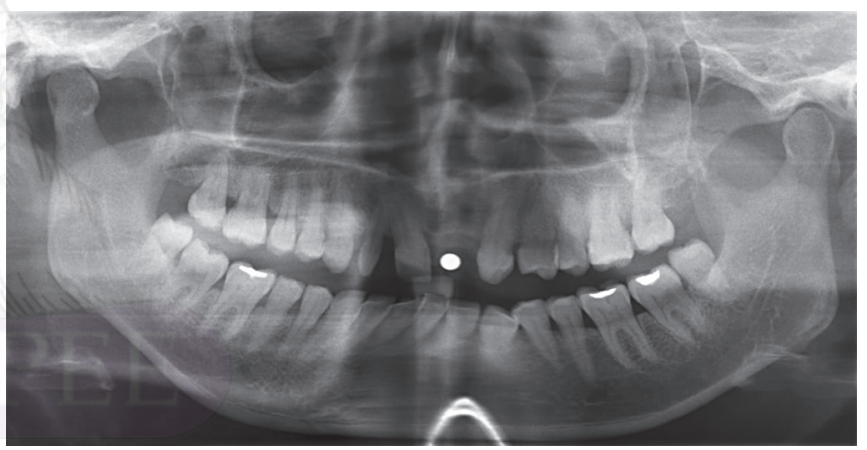

Fig. 2: Orthopantomogram showing periodontally healthy adjacent teeth and adequate bone support in relation to 21

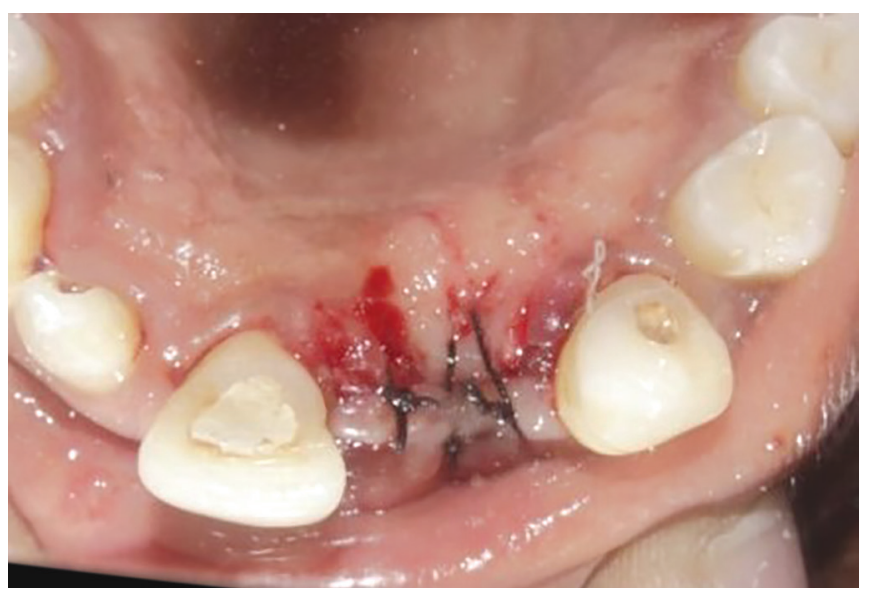

Fig. 4: Flaps approximated using simple interrupted sutures 


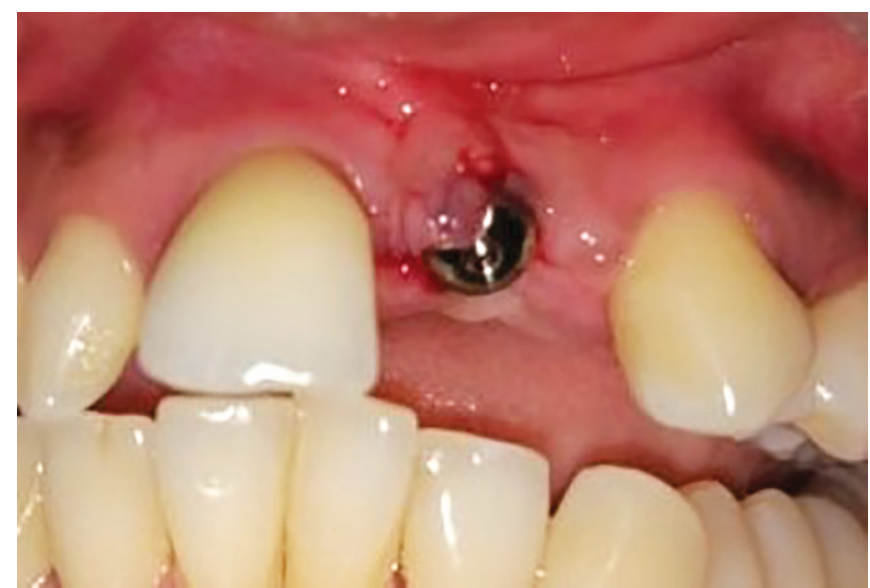

Fig. 5: Healing abutment placed in relation to 21

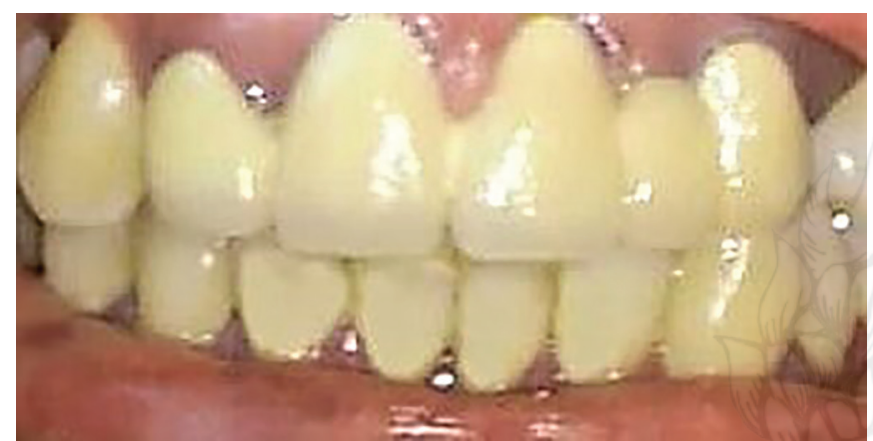

Fig. 7: Six months postoperative picture following all ceramic crown placement

drawing a detailed treatment plan is necessary to define a functional and prosthetic rehabilitation.

Although splinting natural teeth with implants is considered as a second choice of treatment, it can be used for reasons relating to maintaining proprioception, financial issues, anatomical structures, and preference of the patient. ${ }^{9-12}$

Splinting teeth to implants broadens treatment possibilities, reduces cost for replacement of teeth by reducing the implant abutments required for restoration and also preserves the adjacent papilla for esthetic and functional concerns. ${ }^{13}$

Various prosthetic techniques are available to restore lost teeth, which depends on the arrangement, status and number of the residual teeth, patient desires, and adequacy of the bone. It was believed that when a tooth and implant was used as an abutment, the stress on the implant increases causing the implant to fail. However, tooth can be splinted to implants when the teeth is periodontally stable and when rigid connectors are used..$^{14}$

The technical problems are implant failure, tooth intrusion, cement bond breakdown, abutment tooth fracture, screw loosening, fracturing of veneers, and prosthesis fracture.

Biologic complications such as periimplantitis, endodontic problems, loss of abutment teeth/implant, caries, and root fracture may also occur. ${ }^{13}$

Keeping in mind the technical and biologic complication, treatment was planned for the patient's needs and prosthetic adjustments.

In this case report, natural teeth and implant were splinted, considering the adjacent peg laterals, flared right central incisors, and mesially tilted canine. The patient's denial for extraction of the

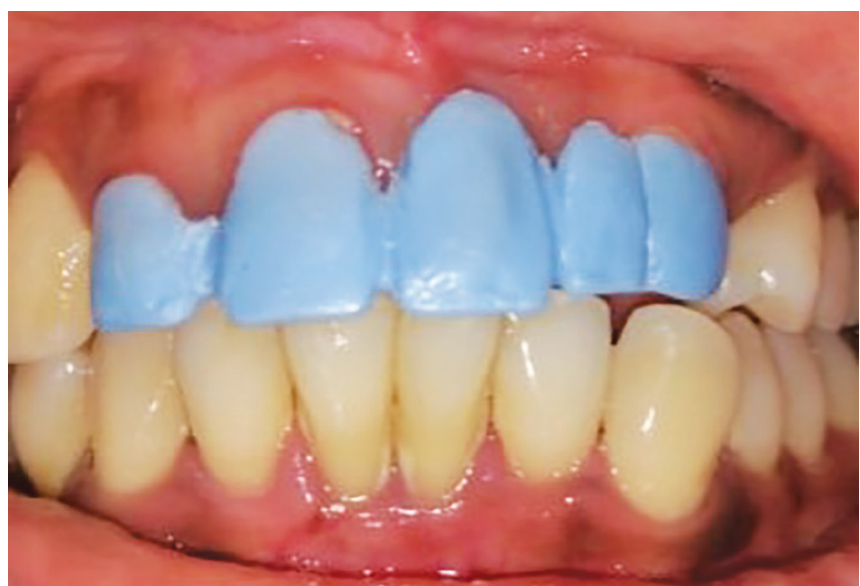

Fig. 6: Mock up trial for 12 (peg laterals), 11 (flared), 21 (implants), 22 (pontic), 23 (mesially tilted)

adjacent teeth and orthodontic treatment lead to the planning of the above treatment.

Previously published case reports by Kovacs, ${ }^{15}$ Linsen et al., ${ }^{16}$ Marcantonio et al., ${ }^{17}$ and Kreissl et al., ${ }^{18}$ demonstrated that splinting of implants with natural teeth can be helpful in restoring esthetics, phonetics, and function.

Here the patient's phonetics improved, and she was satisfied with the prosthesis. Connecting tooth with implants was also used to support distraction osteogenesis devices to allow successful bone augmentation. Hence, splinting of implants with natural teeth can be an alternate treatment option in some clinical indications which provide solution to functional, anatomical, and esthetics problems. It is also a practical option, when preference of the patient and financial issue hinders the successful use of conventional freestanding implants. ${ }^{3}$

Becker et al. suggested that an implant can be splinted with two natural teeth when nonrigid connectors are used. ${ }^{19}$

Brägger et al. suggested that implants supported with natural teeth had lesser amount of failure rates when compared with prosthesis supported with implant alone. ${ }^{20}$

So in this case report, the prosthesis was fabricated in such a way that all centric and eccentric contacts in occlusion were avoided to prevent technical failure. Moreover, the prosthesis was also provided with correction of anatomical variations to provide an esthetic smile.

\section{Conclusion}

Anterior functional and esthetic rehabilitation was achieved successfully in this patient. Splinting of the adjacent teeth with implant helped in achieving an esthetic smile without compromising the patient's preferences. The patient was satisfied with the final esthetic appearance.

\section{References}

1. Albarrak AA, AIRumaih HS, Al-Humaidan A, Al-Thobity AM, Alshahrani FA. Multidisciplinary approach with predictable esthetics: a case report. Saudi Dent J 2019;31(Suppl):S89-S95. DOI: 10.1016/ j.sdentj.2019.01.007.

2. El Askary AE. Multifaceted aspects of implant aesthetics: the anterior maxilla. Implant Dent 2001;10(3):182-191. DOI: 10.1097/00008505200107000-00008.

3. Al-Omiri MK, Al-Masri M, Alhijawi MM, Lynch E. Combined implant and tooth support: an up to date comprehensive overview. Int J Dent 2017;2017:6024565. DOI: 10.1155/2017/6024565. 
4. Honsy M, Duyck J, van Steenberghe D, Naert I. Within-subject comparison between connected and non connected tooth to implant fixed partial prosthesis: up to 14 year follow up study. Int J Prosthodont 2000;13(4):340-346.

5. Nickenig HJ, Spiekermann H, Wichmann M, Andreas SK, Eitner S. Survival and complication rates of combined tooth implantsupported fixed and removable partial dentures. Int J Prosthodont 2008;21(2):131-137.

6. Fardal O, Linden GJ. Long term outcomes for cross arch stabilizing bridges in periodontal maintenance patients-a retrospective study. J Clin Periodontol 2010;37(3):299-304. DOI: 10.1111/j.1600051X.2009.01528.x.

7. Belser UC, Mericske-Stern R, Bernard JP, Taylor TD. Prosthetic management of the partially denate patient with fixed implant restorations. Clin Oral Implants Res 2000;11(Suppl 1):126-145. DOI: 10.1034/j.1600-0501.2000.011S1126.x.

8. Shenoy VK, Rodrigue SJ, Prashanthi E, Saldanha SJ. Tooth implant supported prosthesis: a literature review. J Interdiscip Dent 2013;3(3):143. DOI: 10.4103/2229-5194.131198.

9. Laufer BZ. Splinting osseointegrated implants and natural teeth in rehabilitation of partially edentulous patients. Part II: principles and applications. J Oral Rehabil 1998;25(1):69-80. DOI: 10.1046/j.13652842.1998.00583.x.

10. Salvi GE, Lang NP. Changing paradigms in implant dentistry. Crit Rev Oral Biol Med 2001;12(3):262-272.DOI: 10.1177/10454411010120030501.

11. Rangert B, Gunne J, Sullivan DY. Mechanical aspects of a Branemark implant connected to a natural tooth: an in vitro study. Int J Oral Maxillofac Implants 1991;6(2):177-186.

12. Ericsson I, Lekholm U, Branemark PI, Lindhe J, Glantz PO, Nyman S. A clinical evaluation of fixed bridge restorations supported by the combination of teeth and osseointegrated titanium implants.
J Clin Periodontal 1986;13(4):307-312. DOI: 10.1111/j.1600-051X.1986 tb02227.x.

13. Greenstein G, Cavallaro J, Smith R, Tarnow D. Connecting teeth to implants: a critical review of the literature and presentation of practical guidelines. Compendium 2009;30(7):440-453.

14. Newman M, Takei H, Klokkevold P. Carranza's Clinical Periodontology, 11th ed., St. Louis: Mosby; 2012. pp. 414-418.

15. Kovacs AF. Assessment of prosthetic restorations on bone-lockimplants in patients after oral tumour resection. J Oral Implantol 1998;24(2):101-109. DOI: 10.1563/1548-1336(1998)024<0101:AOPROB >2.3.CO;2.

16. Linsen S, Niederhagen B, Braumann B, Koeck B. Functional ad esthetic rehabilitation after mandibular resection in a child using tooth/implant supported distraction device: a case report. Int J Oral Maxillofac Implants 2004;19(4):603-608.

17. Marcantonio E, Coleta RD, Spin-Neto R, Marcantonio Jr E, Pizzol $\mathrm{KE}$, Boeck EM. Use of a tooth implant supported bone in oral rehabilitation: description of a personalized technique. J Oral Maxillofac Surg 2008;66(11):2339-2344. DOI: 10.1016/j.joms.2008. 06.031.

18. Kreissl ME, Heydecke G, Metzger MC, Schoen R. Zygoma implant supported prosthetic rehabilitation after partial maxillectomy using surgical navigation: a clinical report. J Prosthet Dent 2007;97(3): 121-128. DOI: 10.1016/j.prosdent.2007.01.009.

19. Becker CM, Kaiser DA, Jones JD. Guidelines for splinting implants. J Prosthet Dent 2000;84(2):210-214. DOI: 10.1067/mpr.2000. 108672.

20. Brägger U, Aeschlimann S, Bürgin W, Hämmerle $\mathrm{CH}$, Lang NP. Biological and technical complications and failures with fixed partial dentures (FPD) on implants and teeth after four to five years of function. Clin Oral Implants Res 2001;12(1):26-34. DOI: 10.1034/j.16000501.2001.012001026.x. 